\title{
PLC Teaching Reform And Practice Based On CDIO Engineering Education Mode
}

\author{
Ping Xin ${ }^{1, a}$, Dejun Liu ${ }^{2, a,{ }^{*}}$ and Hongtao $\mathrm{Mi}^{3, \mathrm{a}}$ \\ ${ }^{1}$ BeiHua University, Jilin City Longtan Hill Street No. 1, JiLin, China \\ ${ }^{2}$ BeiHua University, Jilin City Longtan Hill Street No. 1, JiLin, China \\ ${ }^{3}$ BeiHua University,Jilin City Longtan Hill Street No. 1, JiLin, China \\ a359411897@qq.com, 14145277@qq.com,a17207527@qq.com
}

Keywords: Engineering education, PLC, teaching reform, CDIO, Applied talents.

\begin{abstract}
PLC practice teaching should adhere to the training of professional ability as the goal, the task driven as the guidance, the curriculum knowledge and ability into the practice of the project. Focus on cultivating students' project construction, system design and PLC design, debugging ability, training students' innovation ability and organizational coordination ability based on the CDIO mode of curriculum practice training. The purpose of this paper is to study a kind of teaching method of CDIO model based on PLC, from the two aspects of teaching content and laboratory construction meet the "requirements" and "doing" science, and finally construct the CDIO practice of the innovation of education ideas based on laboratory.
\end{abstract}

\section{Introduction}

The traditional teaching process is the "theory", performance in many PLC beginners often spend a lot of energy on the ladder diagram and sequential function chart or various application instructions, while ignoring how PLC is integrated into a practical engineering control system to. The design of an efficient and reliable PLC control system, programming is only one aspect, but not isolated. Learners will have a one-sided understanding of the practical application of PLC if they only pay attention to the PLC programming, it is easy to cause theory and practice disjointed. Fig. 1 shows block diagram for CDIO training.

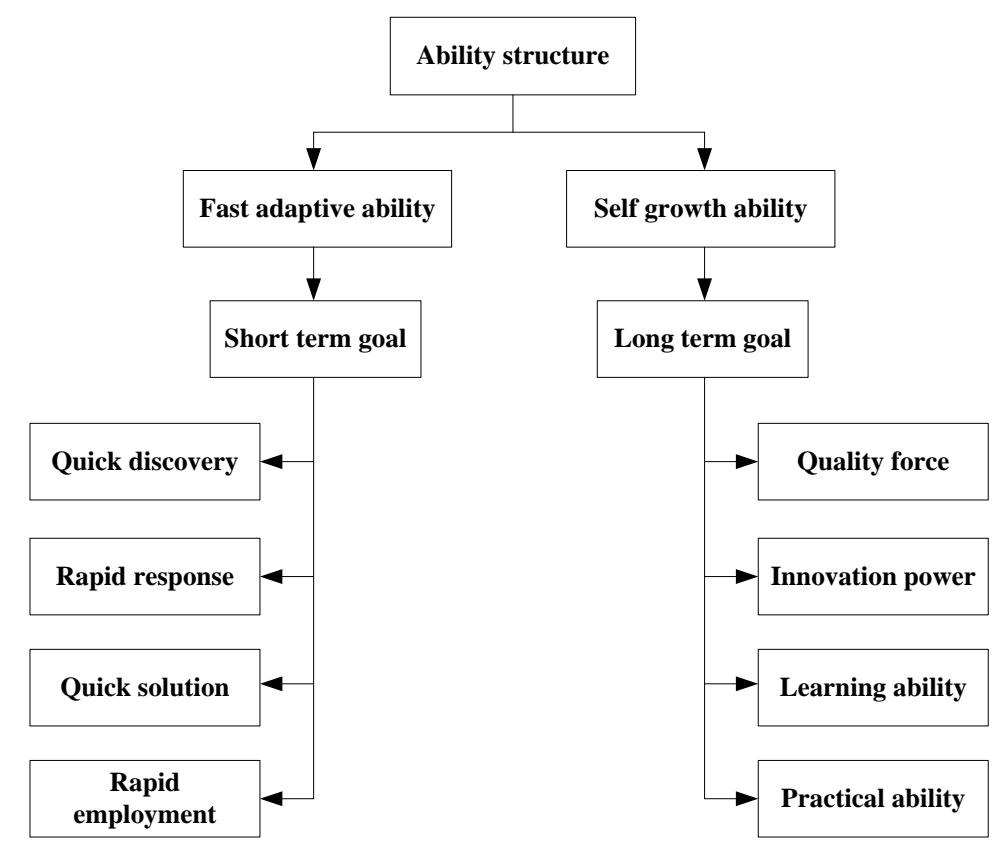

Fig. 1. Block diagram for CDIO training 


\section{The significance of the research topic}

PLC course has strong practicality and application, emphasizing both theoretical knowledge and skills training. According to the requirements of the training objectives, PLC teaching is more practical, highlighting the combination with the actual project, combined with the demand for talent in the production technology posts. Adhere to the culture consciousness of Engineering in PLC teaching, embodies student-centered teaching concept, can stimulate the students' learning motivation, cultivate students' ability of independent thinking, independent research, analysis, problem solving skills, theoretical knowledge to practical ability and team cooperation ability.

At present, the practice teaching reform is to change the contents and methods of the experiment and improve the students' ability of comprehensive analysis. How to carry out all-round and multi angle teaching reform, how to carry out the teaching reform from the angle of the construction of the experimental course, is an important direction of the experimental teaching reform. CDIO model build a good education platform for the construction of engineering awareness. The ability of the students is not from the "teaching", "learning" can really benefit the cultivation of ability.

\section{Literature references}

CDIO engineering education refers to the conception, design, implementation, operation, the knowledge of the curriculum is contented into a number of teaching projects around the project organization and the process of teaching, a new teaching method enable students to directly participate in the whole process of project design, design and debugging.

Combine with engineering practice closely. CDIO engineering education mode is more difficult in the organization of education time, space and resources. According to the CDIO standard design making practice: practice content is set to include two or more "design" practical projects for students starting from the concept of design stage, the stage experience in product design and implementation, production capacity and ability of products and systems to enable students to learn scientific knowledge of product design and engineering application. The project design is the core idea of requiring students to learn by doing, encourage students to active learning and integrated learning, academic activities, promote the students' learning products, production process and system construction skills, communication skills and cooperative learning.

In the process of teaching, the traditional teaching mode of "filling in" is changed into "the student as the main body and the teacher as the leading". In practice, teachers are no longer in the active position, teachers only play a guiding role. The teacher will need to complete the task to the students in the form of project, students work in teams, through independent collect relevant information and puts forward some design topics, and through group discussion, teacher guidance, and finally determine the actual design of the subject. Then the students complete the design of the project and the laboratory independently. This mode has important significance for shaping the students' learning ability and develop the consciousness and spirit of doubt; on the other hand can improve the students' practical interest in autonomous learning, and constantly improve the students' thinking, ability to analyze and solve problems, and construct knowledge ability.

\section{Research scheme and Implementation Measures}

Through the introduction of CDIO model in PLC practice, we can see the huge energy of this kind of education mode. In the process of the implementation of CDIO engineering education model, the scientific organization of teaching process is an effective way to achieve the teaching objectives. To adhere to the project oriented, task driven teaching method, in accordance with the "target task analysis related knowledge task implementation of extended sequential organization knowledge ability test to assess the effect of" teaching, integrated "teaching, learning and doing" integration. According to our preliminary study, the research proposal is shown in Fig.2. 


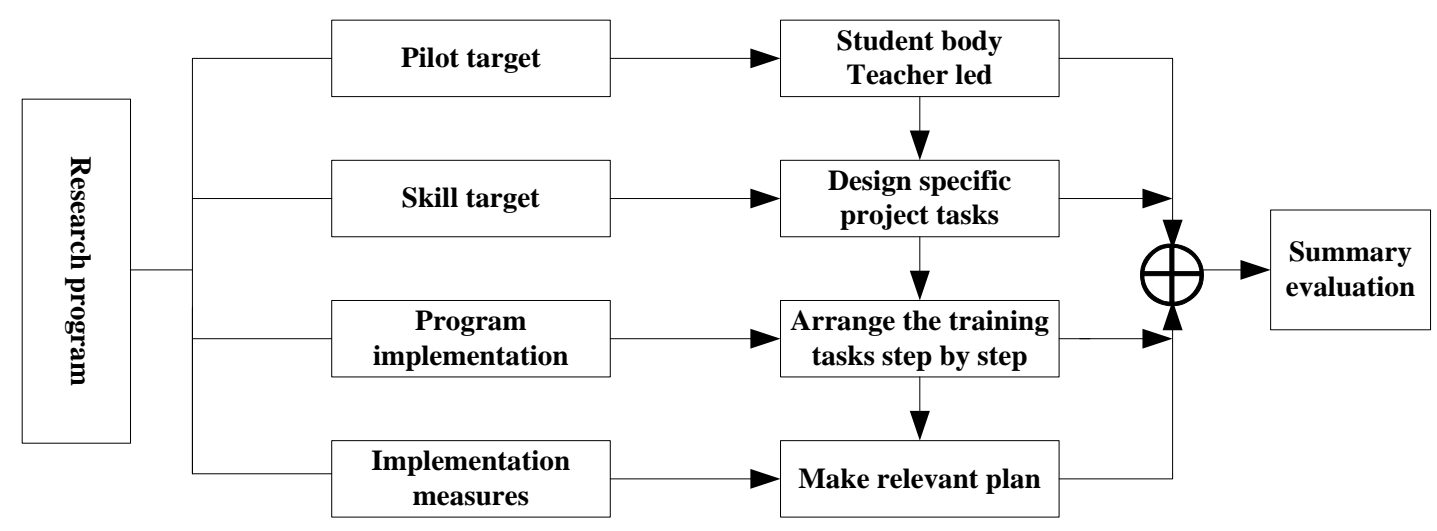

Fig.2. Personalized integrated teaching system

4.1 Pilot scheme. Through the research and pilot, the "student as the main body, the teacher as the leading" teaching mode of research, reasonable decomposition of knowledge and ability points, put forward the PLC practice reform pilot program. Take the engineering application ability as the main line, the project as the carrier, with the application of information technology, through the use of professional application software, network equipment, the real engineering environment and the enterprise actual, inquiry and research of self learning. CDIO concept design teaching, the training of engineering ability and lifelong learning ability as the main line of the project as a carrier, with the application of information technology, the establishment of a multi-level network project, Series modular library, to fully mobilize the enthusiasm of teachers, stimulate students' initiative and creativity, to adapt to social development.

4.2 Refining skill goals. Identify project tasks that are closely related to knowledge and skills, and are moderately difficult. It is not only to meet the needs of the enterprise and job skills, but also to maintain the systematic and integrity of PLC knowledge. Financial knowledge, ability training, quality development as a whole, the design of teaching and learning, through the implementation of the project to do secondary school, secondary school, learning. To create a real engineering environment, strengthen practical teaching. Case teaching is adopted in the real engineering environment of the campus practice base, and the students' engineering consciousness and practical ability are cultivated. Practice base for windows, based on the research project as the carrier, the development of scientific research in industry and Regional Teachers' actual production and society together, improve the academic level of the teachers' scientific research ability, teaching content, tracking dynamic frontier.

4.3 Pilot program implementation. In the implementation process, as from simple to complex, step by step way to arrange the task order, in the introduction of engineering cases, and pay attention to grasp the overall difficulty of practice content, and each task better targeted training, to fully embody the corresponding knowledge learning and ability. Through social practice, to internships, enable students to broaden their horizons, broaden the thinking and understanding of the society, the right to self positioning.

4.4 Pilot program implementation. Training objectives "PLC application technology" Curriculum of basic knowledge and practical skills, put forward PLC practice reform scheme; modify "PLC application technology" course teaching syllabus, syllabus, outline of practice; laboratory construction planning of CDIO mode, with related experimental equipment, creating the PLC Innovation Lab; put forward PLC application to the reform practice the relevant departments of the relevant personnel training; teaching; research, promotion of pilot experience. 


\section{Summary}

Based on the economic and social development of science and technology, industrial automation talents practical innovation ability and comprehensive quality requirements, the project as the carrier, the cultivation of practical ability for the purpose of cultivating students' practical ability in the real engineering environment. Deepen the integration of knowledge, ability and quality of the application of the characteristics of personnel training mode, the development of enterprise personnel to participate in the practice of student assessment mechanism to develop a close combination with the enterprise application of talent.

\section{Acknowledgement}

This research was financially supported by the Education Department Project of Jilin Province: (Education Department of Jilin Province [2016]32nd); The Education Department of the Ministry of education higher education professional teaching steer, Project approval number(DQJZW2016002) ; Education and teaching research topics of Beihua University (BHDQ31).

\section{References}

[1] A. J. Basin, A. A . Hakim, Curriculum assessment as a direct tool in ABET outcomes assessment in a chemical programmer, European Journal of Engineering Education, vol.15, pp. 489 505, 2016.

[2] R. Pert ova, A. Tiebreak, T. M. Sob, An Electronic Web based Assessment System, Journal of STEM Education, Vol.7, No3, pp. 44-57, 2015.

[3] Z. J. Wu, J. Q. Li, C. L. Huang, Adhere to the five attention, promote the five changes, cultivating engineering excellence, Higher engineering education research, Vol. 15, pp. 489 505, 2013.

[4] F. M. Kong, such as the construction of road of the applied university, Peking University press, China 2006.

[5] Y. M. Sun, L. Guo, About planar affine nonlinear system of global asymptotic controllability, Chinese science, Vol. 35, pp. 830-839, 2013.

[6] D. Z. Cheng, Controllability of Switched Bilinear Systems, IEEE Trans. on Automatic Control, Vol.50, pp. 511-515, 2005.

[7] D. Z. Cheng, R. Ortega, E. Panatela, On port controlled Hamiltonian systems, In Advanced Robust and Adaptive Control-Theory and Applications, Vol. 10, pp. 3-16, 2015.

[8] H. X. Yang, Reform of personnel training mode: a report on the pilot reform of the national educational system, Research on Higher Education in China, Vol. 10, pp. 35-39, 2014.

[9] W. Zhang, Y. L Du, The realistic reflection and contemporary innovation of talent cultivation model, educational research, Vol. 01, pp. 122-127, 2015.

[10] Y. Zhang, Y. T. Zhang, Guided by the third industrial revolution: the strategic choice for the development of Higher Engineering Education in China, Education research, Vol. 5, pp. 47-52, 2014.

[11]H. Q. Zhu, The essence and evaluation of Educational Modernization: what kind of educational modernization we need to study, Education Research, Vol. 15, pp. 50-55, 2013. 